


\title{
Aplicação de métodos baseados em teoria da utilidade multi-atributo ao problema de ordenação de jogadores de basquetebol
}

\author{
Vitor Fernandes Santos*, Leonardo Tomazeli Duarte
}

\begin{abstract}
Resumo
A tomada de decisão é algo frequente em nossas vidas e não seria diferente no esporte. Ao término da temporada da NBA, jornalistas votam e elegem os 15 melhores jogadores, que são distribuídos em três equipes. O problema é que a tomada de decisão é subjetiva, o que pode ocasionar inúmeros vieses. Para tentar minimizá-los, existem vários métodos matemáticos de apoio à tomada de decisão, sendo que os métodos baseados na teoria da utilidade multiatributo estão entre os mais populares. Extensões mais modernas do MAUT são capazes de corrigir um problema deveras relevante: a interação entre critérios. Um exemplo dessas extensões se encontra nos métodos de agregação baseados na integral de Choquet. Nesse trabalho, estudaremos a aplicação do MAUT (e extensões baseadas na integral de Choquet) no banco de dados da temporada 2012/2013 da NBA, obtendo assim os 15 melhores jogadores de maneira objetiva. O foco é demonstrar os vieses de decisão do subjetivo, nos quais jogadores com boas estatísticas podem ter ficado de fora dos melhores.
\end{abstract}

\section{Palavras-chave:}

Basquetebol, Pesquisa Operacional, Integral de Choquet

\section{Introdução}

A tomada de decisão é algo frequente em toda a nossa vida, sendo um processo subjetivo, variável de pessoa para pessoa. No esporte, o subjetivo também acontece. Ao final de cada temporada da NBA (National Basketball Association), a liga de basquete dos Estados Unidos da América e Canadá, uma centena de jornalistas vota e elege os 15 melhores jogadores da temporada e os distribuem por times. Existem vários métodos matemáticos que auxiliam na tomada de decisão. Uma possível opção são os métodos de decisão baseados na teoria da utilidade multi-atributo (MAUT) [1]. Extensões mais modernas do MAUT são capazes de corrigir um problema deveras relevante: a interação entre critérios. Um exemplo dessas extensões se encontra nos métodos de agregação baseados na integral de Choquet. Neste presente projeto, tal método e suas extensões foram aplicados no banco de dados da temporada 2012-2013 da NBA, de forma a obtermos os 15 melhores jogadores da liga. Ao final, foi realizada a verificação dos resultados do método com as escolhas dos jornalistas.

\section{Resultados e Discussão}

Nesses resultados, conseguimos analisar o efeito causado pela frequente exposição na mídia de determinados jogadores e times. Jogadores consagrados que não apresentam boas estatísticas, são preferidos pelos jornalistas no momento de montagem dos times. A finalidade desta pesquisa é mostrar esse viés de decisão, no qual as pessoas têm a tendência de escolher 0 tradicional, mesmo sem grandes resultados. O tradicional geralmente está na mídia há mais tempo, o que causa um conforto maior nas pessoas para que sejam escolhidos [2]. Mas, o escore de $73 \%$ do teste se deve, em parte, a maneira como o esporte é visto pelas ligas norte americanas. O uso das estatísticas se faz muito presente nas ligas existentes por lá, o que acaba por minimizar os riscos e as injustiças.
Tabela 1. Time do Método (jogadores com asterisco estão presentes em ambos os times)

\begin{tabular}{|c|c|c|}
\hline TIME 1 & TIME 2 & TIME 3 \\
\hline L. James* $^{\star}$ & P. George* & K. Durant \\
\hline T. Duncan $^{\star}$ & B. Griffin & D. West \\
\hline D. Howard* & Al Horford & J. Noah \\
\hline C. Paul $^{*}$ & S. Curry & T. Parker \\
\hline J. Harden $^{\star}$ & K. Bryant & D. Wade* \\
\hline
\end{tabular}

\section{Conclusões}

Então, o foco desse presente projeto não é ser mais um que procura a exclusão do subjetivo, mas, consideramos que existe outra possibilidade, que minimize os riscos. No estudo, cerca de $73 \%$ dos escolhidos pelos jornalistas entraram no time do método também. Serão necessários mais estudos de tomada de decisão voltados para o esporte, para tentarmos diminuir os vieses. Em virtude da formatura do aluno, o projeto teve que ser interrompido previamente, não sendo possível aplicação da Integral de Choquet nos testes da iniciação, porém terá continuação no mestrado do aluno, iniciado em fevereiro/2016.

\section{Agradecimentos}

Agradecimentos em especial a minha família por me dar todo o apoio, ao professor orientador Leonardo Tomazeli Duarte pelo suporte em toda a pesquisa e ao PIBIC pelo financiamento do projeto.

${ }^{1}$ Figueira, J.; Greco, S. Multiple criteria decision analysis: state of the art surveys. Springer, 2004. 